\title{
Subcellular Distribution of Azithromycin and Clarithromycin in Rat Alveolar Macrophages (NR8383) in Vitro
}

\author{
Kohei Togami, ${ }^{a}$ Sumio Chono, ${ }^{* a}$ and Kazuhiro Morimoto ${ }^{b}$ \\ ${ }^{a}$ Division of Pharmaceutics, Hokkaido Pharmaceutical University School of Pharmacy; 7-1 Katsuraoka-cho, Otaru, \\ Hokkaido 047-0264, Japan: and ${ }^{b}$ Faculty of Pharmaceutical Sciences, Teikyo Heisei University; 4-21-2 Nakano, \\ Nakano-ku, Tokyo 164-8530, Japan. \\ Received May 30, 2013; accepted July 3, 2013
}

Azithromycin (AZM), a 15-membered ring macrolide antimicrobial agent, has an antibacterial spectrum that includes intracellular parasitic pathogens that survive or intracellularly multiply in alveolar macrophages (AMs). The subcellular distribution of AZM in AMs was evaluated in vitro in comparison with clarithromycin (CAM). AZM and CAM (50 $\mu \mathrm{M})$ were applied to the NR8383 cells, used as an in vitro model of $\mathrm{AMs}$, followed by incubation at $37^{\circ} \mathrm{C}$ or $4^{\circ} \mathrm{C}$. The total amount of $\mathrm{AZM}$ in cells and subcellular distribution (cell fractionation) was determined after incubation. High level of AZM accumulation was observed in the NR8383 cells at $37^{\circ} \mathrm{C}$, and the equilibrium intracellular to extracellular concentration ratio (I/E ratio) was approximately 680, which was remarkably higher than that of CAM (equilibrium $I / E$ ratio=28). The intracellular accumulation of AZM and CAM was temperature dependent. In addition, AZM distributed to the granules fraction including organelles and soluble fraction including cytosol in the NR8383 cells, whereas CAM mainly distributed in soluble fraction. The amount of AZM in the granules fraction was markedly reduced in the presence of ammonium chloride for increase in intracellular $\mathrm{pH}$. These results indicate that AZM is distributed in acidic compartment in AMs. This study suggests that high AZM accumulation in the NR8383 cells is due to the trapping and/or binding in acidic organelles, such as lysosomes.

Key words macrolide antimicrobial agent; intracellular accumulation; granules fraction; acidic organelle; intracellular parasitic pathogen

Azithromycin (AZM) is a 15-membered ring macrolide antimicrobial agent, and is an azalide synthesized from erythromycin. ${ }^{1)}$ AZM has a wide antibacterial spectrum that covers major gram positive and gram negative bacteria. ${ }^{2}$ In addition, activity of AZM against intracellular parasitic pathogens such as Chlamydia pneumoniae and Legionella pneumophila has been reported. ${ }^{3,4)}$ Moreover, the pharmacokinetic characteristics of AZM are unique, with higher distribution in various tissues including lung, kidney, spleen, and liver and longer elimination half-life than other macrolides. ${ }^{5,6}$ In particular, AZM is remarkably concentrated in various phagocytes such as polymorphonuclear neutrophils (PMNs) and peritoneal macrophages than other macrolides. ${ }^{7-9)}$ Therefore, AZM is clinically effective even at low plasma concentrations in various tissue and phagocytic infections. ${ }^{10)}$

Alveolar macrophages (AMs) are found within the alveolar epithelial lining fluid on the alveolar surface. ${ }^{11)}$ AMs represent the first line of defense against inhaled pathogens. ${ }^{12)}$ However, intracellular parasitic pathogens, such as Chlamydia pneumoniae and Legionella pneumophila, which are taken up by AMs via phagocytosis are resistant to the biocidal mechanisms of AMs and survive or intracellularly multiply within AMs. ${ }^{13,14)}$ The survival of pathogens within AMs after phagocytosis often results in chronic and refractory infections. Optimal therapy for respiratory infections caused by these pathogens would include the use of antimicrobial agents that accumulate in AMs. ${ }^{15)}$ The accumulation of various antimicrobial agents such as $\beta$-lactams, quinolones, macrolides, and ketolides in AMs has been reported. ${ }^{16-20)}$ However, it has recently been reported that sterilization of intracellular parasitic pathogens requires not only high accumulation of

The authors declare no conflict of interest. antimicrobial agents in AMs but also distribution in infected intracellular compartments (cytosol and lysosomes). ${ }^{21,22)}$ In addition, the minimal inhibitory concentrations (MICs) should be considered intracellular environment such as intracellular $\mathrm{pH}$, various enzymes, and bacterial spore-formers. ${ }^{22)}$ The concentration of antimicrobial agents in infected intracellular compartments must be exceeded these MICs. Therefore, subcellular distribution of antimicrobial agents in AMs is of particular importance, and should be investigated for further understanding.

We have previously reported high concentrations of AZM accumulated into AMs, in spite of lower permeation to the alveolar surface from plasma than other macrolide antimicrobial agents. ${ }^{23,24)}$ However, the subcellular distribution of AZM in AMs has not been reported yet. In this study, the subcellular distribution of AZM in the NR8383 cells, used as an in vitro model of cultured AMs was evaluated compared with clarithromycin (CAM), a 14-membered ring macrolide antimicrobial agent

\section{MATERIALS AND METHODS}

Materials AZM was purchased from LKT Laboratories, Inc. (St. Paul, MN, U.S.A.). CAM, ammonium chloride, and propranolol hydrochloride were purchased from Wako Pure Chemical Industries, Ltd. (Osaka, Japan). All other reagents were of analytical grade and commercially available.

Accumulation Experiments in NR8383 The NR8383 cells (American Type Culture Collection, Manassas, VA, U.S.A.) were used as an in vitro model of cultured SpragueDawley rat AMs. Cells were cultured in RPMI-1640 medium (Sigma Chemical Co.) containing 10\% fetal bovine serum (Sigma Chemical Co.) for $14-18 \mathrm{~d}$ before the accumulation 
experiments were started. Cells were suspended at a concentration of $1.25 \times 10^{6}$ cells $/ \mathrm{mL}$ in RPMI 1640 medium containing $1 \%$ fetal bovine serum. Subsequently, aliquots $(200 \mu \mathrm{L})$ of the cell suspension were transferred to 96-well culture plates (Becton Dickinson, Lincoln Park, NJ, U.S.A.), and the plates were incubated for $90 \mathrm{~min}$ at $37^{\circ} \mathrm{C}$ with $5 \% \mathrm{CO}_{2}$. After incubation, non-adherent cells were removed, serum-free medium (Gibco BRL, Life Technologies, Rockville, MD, U.S.A.) was subsequently added to cells. AZM and CAM $(50 \mu \mathrm{M})$ were applied to the NR8383 cells, cells were then incubated at $37^{\circ} \mathrm{C}$ or $4^{\circ} \mathrm{C}$. The medium was removed by aspiration at designated times and washed three times with ice-cold phosphate buffered saline (PBS). Cells were then extracted using $400 \mu \mathrm{L}$ $0.1 \mathrm{M} \mathrm{NaOH}$. To calculate AZM and CAM concentrations in the NR8383 cells, the intracellular volume in the NR8383 cells was determined by a velocity-gradient centrifugation technique using ${ }^{3} \mathrm{H}$-water; estimation revealed a mean value of $4.2 \mu \mathrm{L} / \mathrm{mg}$ cell protein. ${ }^{25}$ ) The AZM and CAM concentrations in each sample were measured by HPLC as reported previously. ${ }^{23)}$ The protein concentration in the NR8383 cells extracts was determined using Coomassie protein assay reagent (Pierce Chemical Company, Rockford, IL, U.S.A.) with bovine serum albumin as a standard. ${ }^{26}$

Subcellular Distribution Experiments in NR8383 The NR8383 cells were first treated with AZM and CAM $(50 \mu \mathrm{M})$ at $37^{\circ} \mathrm{C}$ or $4^{\circ} \mathrm{C}$, cells were then collected and homogenized in $250 \mathrm{~mm}$ sucrose, $1 \mathrm{~mm}$ ethylene glycol-bis(2-amino ethylether)- $N, N, N^{\prime}, N^{\prime}$-tetra-acetic acid (EGTA), and $3 \mathrm{~mm}$ imidazole ( $\mathrm{pH}$ 7.4) as previously described. ${ }^{27)}$ In the group treated with ammonium chloride, the NR8383 cells were first pre-treated with $10 \mathrm{~mm}$ ammonium chloride at $37^{\circ} \mathrm{C}$ for $30 \mathrm{~min}$ for neutralization in lysosomes, then treated with $\mathrm{AZM}$ and CAM $(50 \mu \mathrm{M})$ at $37^{\circ} \mathrm{C}$. The homogenate was separated into a nuclear fraction (including nuclei and cell bulk) and another extract by low speed centrifugation $\left(1600 \times \boldsymbol{g}, 10 \mathrm{~min}, 4^{\circ} \mathrm{C}\right)$. This extract was separated into a granules fraction (including intracellular organelles) and a soluble fraction (including cytosol) by high speed centrifugation $\left(145000 \times \mathbf{g}, 30 \mathrm{~min}, 4^{\circ} \mathrm{C}\right)$. In each fraction, the amount of AZM and CAM was measured by HPLC as reported previously. ${ }^{23)}$ The activities of lactate dehydrogenase as a marker of cytosol and $\mathrm{N}$-acetyl-betaglucosaminidase as a marker of lysosomes were assayed in each fraction. ${ }^{27)}$ In brief, the activity of lactate dehydrogenase (LDH) was assayed by the LDH-Cytotoxic Test Wako (Wako Pure Chemical Industries, Ltd.). The activity of $\mathrm{N}$-acetylbeta-glucosaminidase was assayed by cleavage of nitrophenol from $p$-nitrophenyl-beta-acetyl-D-glucosamide. Briefly, the soluble fractions $(500 \mu \mathrm{L})$ mixed with $10 \mathrm{~mm} p$-nitrophenylbeta-acetyl-D-glucosamide dissolved in sodium citrate buffer (20 mm, pH 4.4), and then the mixture was incubated at $37^{\circ} \mathrm{C}$ for $15 \mathrm{~min}$. The reaction was stopped with sodium carbonate buffer $(10 \mathrm{~mm}, \mathrm{pH} 10.7)$, and the reaction product was measured by spectrophotometry at $405 \mathrm{~nm}$. Cytochrome $c$ oxidase as a marker of mitochondria was assayed by the Mitochondria activity assay kit (BioChain Institute Inc., Newark, CA, U.S.A.).

Accumulation Experiments Using the Isolated Granules Fraction from NR8383 The granules fraction of the NR8383 cells was prepared as described in the previous section. AZM and CAM $(50 \mu \mathrm{M})$ were first dissolved in $250 \mathrm{~mm}$ sucrose, $1 \mathrm{~mm}$ EGTA and $3 \mathrm{~mm}$ imidazole ( $\mathrm{pH}$ 7.4) were ap- plied to the granules fraction of $200 \mu \mathrm{g}$ protein, then the fraction was incubated at $37^{\circ} \mathrm{C}$. After incubation, samples were centrifuged at $145000 \times \boldsymbol{g}$ for $30 \mathrm{~min}$ at $4^{\circ} \mathrm{C}$. CAM and $\mathrm{AZM}$ concentrations in the supernatant were measured using HPLC. In the accumulation inhibition experiments, the granules fraction of the NR8383 cells was pre-treated with [ammonium chloride $(10 \mathrm{~mm})$ and propranolol $(10 \mathrm{~mm})]$ basic compounds at $37^{\circ} \mathrm{C}$ for $30 \mathrm{~min}$ for neutralization in lysosomes. Subsequently, the granules fraction was treated with AZM and CAM $(50 \mu \mathrm{M})$ at $37^{\circ} \mathrm{C}$ for $30 \mathrm{~min}$.

Statistics Statistical analysis was performed by MannWhitney U-test and Dunnett's test using Statview software (Abacus Concepts Inc., CA, U.S.A.). A value of $p<0.05$ was considered to be the minimum level of statistical significance.

\section{RESULTS}

Accumulation of AZM and CAM in NR8383 The time profiles of intracellular AZM and CAM accumulation in the NR8383 cells are shown in Fig. 1. The AZM accumulation reached saturation after $4 \mathrm{~h}$ of incubation at $37^{\circ} \mathrm{C}$. The equilibrium intracellular to extracellular concentration ratio (I/E ratio) of AZM was approximately 680, which was remarkably higher than that of CAM (equilibrium I/E ratio=28). AZM and $C A M$ accumulation was temperature dependent. The rate of accumulation of AZM and CAM at $4^{\circ} \mathrm{C}$ was considerably slower than that at $37^{\circ} \mathrm{C}$, and the maximum $\mathrm{I} / \mathrm{E}$ ratios were 385 and 7.8 , respectively.

Subcellular Distribution of AZM and CAM in NR8383 The time profiles of subcellular distribution of AZM and CAM are shown in Fig. 2. $N$-Acetyl-beta-glucosaminidase as a marker of lysosomes and cytochrome $c$ oxidase as a marker of mitochondria were mainly found in the granules fraction ( $>88 \%$ and $>91 \%$, respectively), whereas lactate dehydrogenase as a marker of cytosol was mainly found in the soluble fraction $(>89 \%)$. The subcellular distribution of CAM attained equilibrium after $1 \mathrm{~h}$ incubation when approximately $30 \%$ of CAM was in the granules fraction $(2.1 \mathrm{nmol} / \mathrm{mg}$ protein), with $66 \%$ in the soluble fraction $(4.3 \mathrm{nmol} / \mathrm{mg}$ protein). In contrast, the amount of AZM in the granules fraction increased with time over the course of incubation, reaching an equilibrium after $4 \mathrm{~h}$ incubation when approximately $57 \%$ of AZM was in the granules fraction $(78.1 \mathrm{nmol} / \mathrm{mg}$ protein), with $41 \%$ in the soluble fraction $(56.2 \mathrm{nmol} / \mathrm{mg}$ protein).

Accumulation of AZM and CAM in Granules Fraction of NR8383 Time profiles summarizing accumulation of AZM and CAM in the granules fraction of the NR8383 cells are shown in Fig. 3. Both AZM and CAM were rapidly accumulated in the granules fraction of the NR8383 cells. The accumulation of AZM by the granules fraction was 10-fold higher than that of CAM. The effects of basic compounds on the accumulation of AZM and CAM in the granules fraction of the NR8383 cells are shown in Fig. 4. Both ammonium chloride and propranolol significantly inhibited the accumulation of CAM and AZM. The inhibitory effects of ammonium chloride and propranolol were stronger for AZM than for CAM.

Effect of Basic Compounds and Temperature on the Subcellular Distribution of AZM and CAM in NR8383 The effect of basic compounds and temperature on the subcellular distribution of AZM and CAM between the granules 
(A)

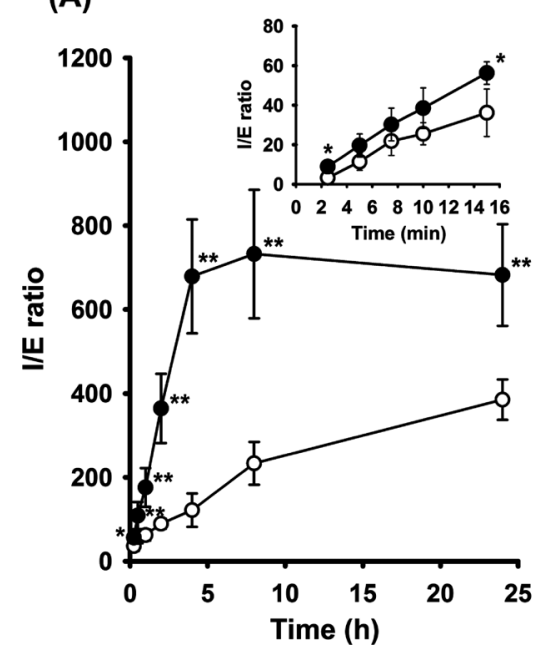

(B)

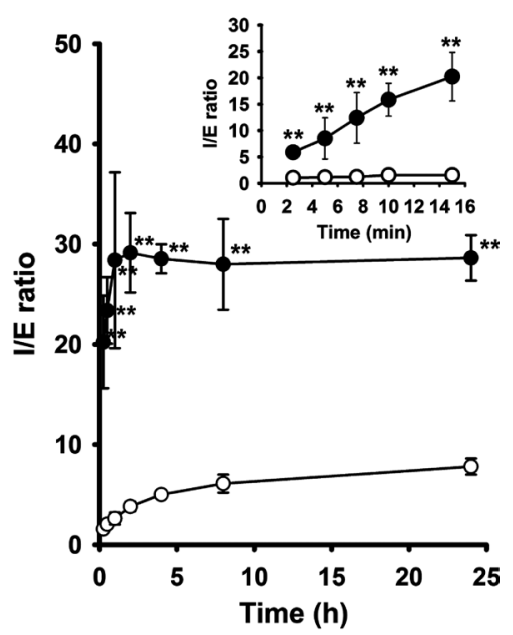

Fig. 1. Time Profiles of the Intracellular Accumulation of AZM (A) and CAM (B) in the NR8383 Cells

AZM and CAM $(50 \mu \mathrm{M})$ were applied to the NR8383 cells, followed by incubation at $37^{\circ} \mathrm{C}$ (closed symbols) or $4{ }^{\circ} \mathrm{C}$ (open symbols). At each time point $(2.5,5,7.5,10,15$, and $30 \mathrm{~min}, 1,2,4,8$, and $24 \mathrm{~h}$ ) after incubation, the intracellular AZM concentration and CAM were determined; the data are shown as the intracellular to extracellular concentration ratio (I/E ratio). Each point represents the mean \pm S.D. $(n=4)$. ${ }^{*} p<0.05$ and ${ }^{* *} p<0.01$ : significantly different from $4{ }^{\circ} \mathrm{C}$.

(A)

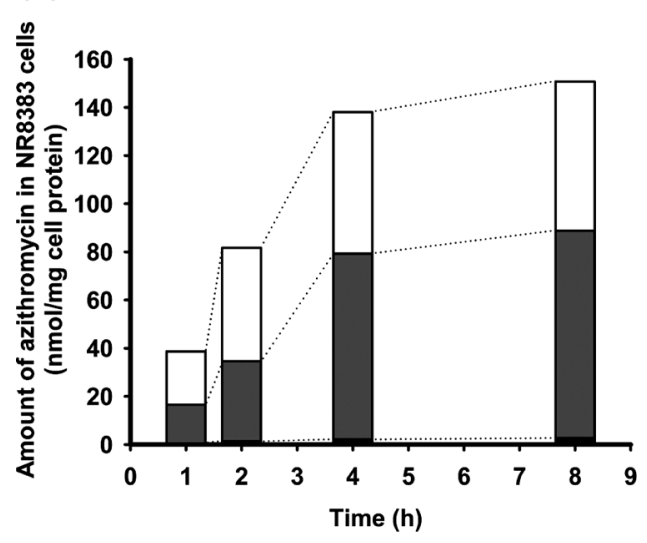

(B)

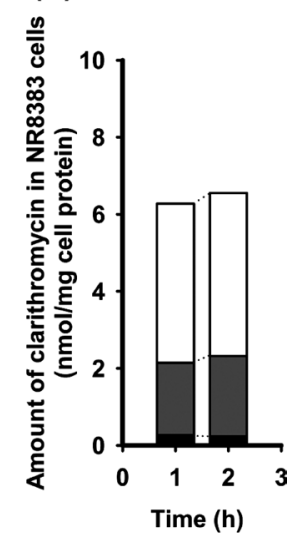

Nuclear fraction $\square$ Granules fraction $\square$ Soluble fraction

Fig. 2. Time Profiles of the Subcellular Distribution of AZM (A) and CAM (B)

AZM and CAM $(50 \mu \mathrm{M})$ were applied to the NR8383 cells, followed by incubation at $37^{\circ} \mathrm{C}$. At each time point $(1,2,4$, and $8 \mathrm{~h})$ after incubation, cells were homogenated and the nuclear, granules, and soluble fractions were collected. The amount of AZM and CAM in each fraction was determined.

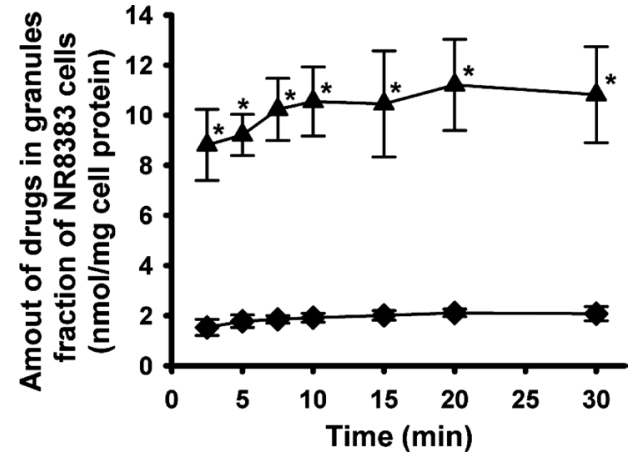

Fig. 3. Time Profiles of AZM (Triangle Symbol) and CAM (Diamond Symbol) Accumulation in the Granules Fraction of the NR8383 Cells

The granules fraction was collected from the NR8383 cells and AZM and CAM $(50 \mu \mathrm{M})$ were applied to the granules fraction of $200 \mu \mathrm{g}$ protein, followed by incubation at $37^{\circ} \mathrm{C}$. After incubation, AZM and CAM accumulation in the granules fraction were determined. Each point represents the mean \pm S.D. $(n=4) . * p<0.01$ : significantly different from CAM. fraction and the soluble fraction is shown in Fig. 5. In the group treated at a temperature of $4^{\circ} \mathrm{C}$, the distribution of AZM and CAM in the soluble fraction was substantially reduced, but little effect was observed on the accumulation in the granules fraction. In contrast, in the group treated with ammonium chloride, AZM and CAM accumulation in the granules fraction was highly reduced.

\section{DISCUSSION}

High levels of AZM accumulation were observed in the $\mathrm{NR} 8383$ cells at $37^{\circ} \mathrm{C}$, and the equilibrium I/E was approximately 680 , which was remarkably higher than that of CAM (Fig. 1). This value was higher compared with the values in other macrophages, such as THP-1 as human macrophage (I/E ratio=26), RAW264.7 as mouse macrophage (I/E ratio $\leqq 250)$, and $\mathrm{J} 774$ as mouse macrophage $(\mathrm{I} / \mathrm{E}$ ratio $\leqq 40)$ cell lines. ${ }^{7,28)}$ Our previous report suggested that high level of AZM ac- 
(A)

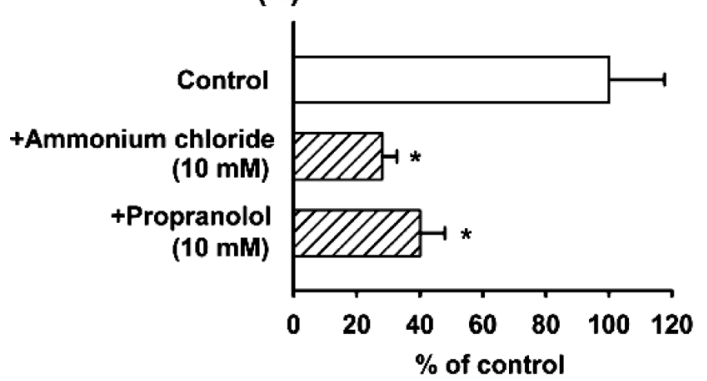

(B)

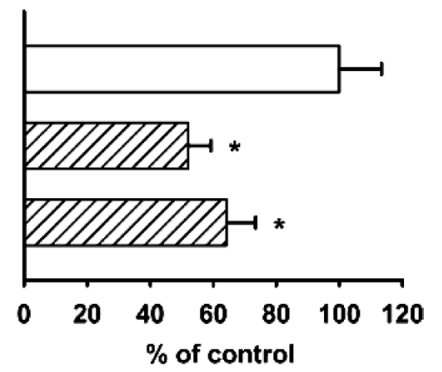

Fig. 4. Effects of Ammonium Chloride and Propranolol as Basic Compounds on the Accumulation of AZM (A) and CAM (B) in the Granules Fraction of the NR8383 Cells

The granules fraction of $200 \mu \mathrm{g}$ protein was first pre-treated with basic compounds $(10 \mathrm{~mm})$ at $37^{\circ} \mathrm{C}$ for 10 min for neutralization in lysosomes, then treated with AZM and CAM $(50 \mu \mathrm{M})$ at $37^{\circ} \mathrm{C}$ for $30 \mathrm{~min}$. After incubation, CAM and AZM accumulation in the fraction was determined to be significantly different from control. Each point represents the mean \pm S.D. $[(n=4) * p<0.01$.]

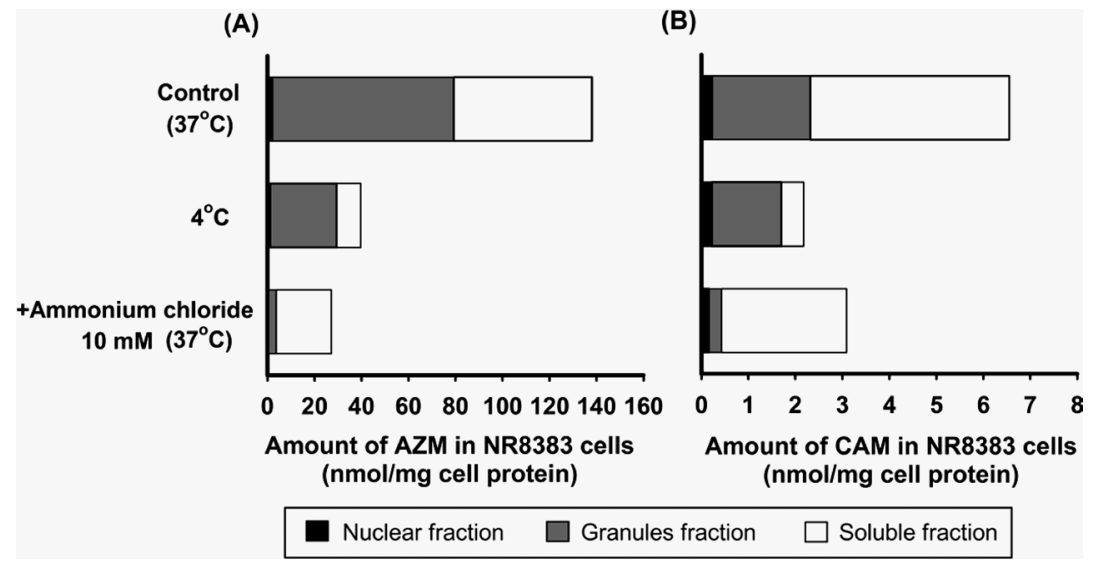

Fig. 5. Effects of Temperature and Ammonium Chloride on the Subcellular Distribution of AZM (A) and CAM (B)

AZM and CAM $(50 \mu \mathrm{M})$ were applied to the NR8383 cells, followed by incubation at $37^{\circ} \mathrm{C}$ or $4{ }^{\circ} \mathrm{C}$ for $4 \mathrm{~h}$ and $1 \mathrm{~h}$ for AZM and CAM, respectively. In the group treated with ammonium chloride, the NR8383 cells were pre-treated with $10 \mathrm{~mm}$ ammonium chloride at $37^{\circ} \mathrm{C}$ for 30 min for neutralization in lysosomes. After incubation, cells were homogenated and the nuclear, granules, and soluble fractions were collected. The amount of AZM and CAM in each fraction was determined.

cumulation in AMs might be mediated by active influx systems. ${ }^{23)}$ Organic anion transporter polypeptides (OATPs), influx transporters, are expressed in macrophages. ${ }^{29)}$ Because AZM is substrate of OATPs, ${ }^{30-32)}$ AZM may be influxed to the intracellular region via OATPs of AMs. Because of the expression of active influx systems such as OATPs on several macrophages, the I/E ratio of AZM might differ in these cells. However, in this study, only temperature dependent accumulation was confirmed. Evaluations of effects of metabolic inhibitors, concentration dependency, and experiments using overexpression or siRNA techniques of active influx systems are necessary to demonstrate the contribution of active influx to intracellular accumulation of AZM. In contrast, at a low temperature $\left(4^{\circ} \mathrm{C}\right)$, the rate of intracellular accumulation of AZM was relatively high when maximum I/E ratio was approximately 390 (Fig. 1). In addition, we have previously reported that the efflux of AZM from AMs was slower than that of CAM. ${ }^{23)}$ These characteristics of intracellular accumulation of AZM in AMs are similar to that of PMN. ${ }^{33)}$ Chanteux et al. have reported that AZM slightly bonds with the lipid bilayers of membrane. ${ }^{34)}$ Therefore, AZM is considered to accumulate in phagocytes mediated by energy independent binding and/or trapping in cells.

The subcellular distribution of AZM reached equilibrium after $4 \mathrm{~h}$ incubation and the drug was mainly found in the granules fraction (Fig. 2). Since the drugs might be released from granules faction while the fraction was prepared, the drugs accumulations in granules fraction were considered to be estimated low. Thus, actual amount of AZM in the granules fraction is considered to be higher than the data shown in this study. AZM accumulation in the isolated granules fraction, including cellular organelles, was rapid and higher than that of CAM (Fig. 3). These results suggested that high AZM accumulation in AMs is mediated by high accumulation in the cellular organelle of AMs. The temperature dependence of initial uptake of AZM was weak in contrast to CAM (Fig. 1). In addition, the amount of AZM in granules fraction was time-dependent and was increased for $4 \mathrm{~h}$ (Fig. 2). These results suggested that the rate-determining step of intracellular accumulation of AZM is considered to be subcellular distribution in the cellular organelle of AMs. The granules fraction of AMs includes lysosomes and mitochondria. Basic compound specific accumulation in lysosomes in membrane impermeable forms was mediated by intralysosomal acidic $\mathrm{pH}^{35)}$ and in mitochondria was mediated by binding to monoamine oxidase. ${ }^{36)}$ Because AZM is also a basic compound, ${ }^{34)}$ it probably distributes to these organelles. AZM accumulation in the granules fraction of the NR8383 cells was markedly inhibited by ammonium chloride and propranolol (Fig. 4). It has been reported that the accumulation of propranolol in AMs is 
inhibited in the presence of basic compounds $\left(\mathrm{p} K_{\mathrm{a}}>7\right)$, such as procaine, lidocaine, and nicotine. This inhibitory effect was considered to be a result of increasing intralysosomal $\mathrm{pH}^{37}$ ) Because AZM has appropriately weak $\mathrm{p} K_{\mathrm{a}}$ values of 8.1 and $8.8,{ }^{34)}$ AZM accumulation in lysosomes of AMs is thought to be high. Ishizaki et al. have reported that the accumulation of basic compounds in lysosomes was several times higher than that in mitochondria. ${ }^{38)}$ These findings indicated that AZM mainly accumulated in lysosomes of AMs mediated by a $\mathrm{pH}$-dependent permeation mechanism. Several antimicrobial agents such as radezolid and telavancin were also highly accumulated in phagocytes via $\mathrm{pH}$-dependent mechanisms. ${ }^{39,40)}$ The accumulation of drugs in lysosomes by $\mathrm{pH}$-dependent permeation mechanism is thought to play a key role in phagocytic drug accumulation. Although CAM was also a basic compound, the accumulation of CAM in the granules fraction was smaller than that of AZM (Figs. 2, 3). Accumulation of certain basic drugs was markedly high in lysosomes by binding and/or aggregation in lysosomes. ${ }^{41)}$ In addition, Haran et al. have reported that basic drug exchange intracellular ammonium ions for extracellular ions. ${ }^{42}$ The ion exchange might be to participate in the intracellular accumulation of basic drugs. These mechanisms might be result in high level of AZM accumulation in lysosomes.

Subcellular distribution of AZM in the granules fraction markedly reduced in the presence of ammonium chloride (Fig. 5). These results support the hypothesis that AZM is accumulated in lysosomes of AMs. Although AZM may not be stable in the lysosomes for extended periods of time and the antibacterial activity of AZM is weak at a low $\mathrm{pH}^{43}$ ) lysosomes represent only $2.5 \%$ of the cell the volume. ${ }^{44)}$ Therefore, it was thought that AZM concentration in lysosomes is markedly higher than in the extracellular concentration; sufficient for treatment of parasitic infections in lysosomes. Our previous report indicated that after oral administration to rats, AZM concentration in AMs was markedly higher than MIC of intracellular parasitic pathogens, such as Chlamydia pneumoniae and Legionella pneumophila. ${ }^{45)}$ These findings suggest that AZM is an especially effective antimicrobial agent for the treatment of respiratory infections caused by intracellular parasitic pathogens which are characterized by subcellular localization in lysosomes such as Legionella pneumophila. ${ }^{22)}$ At a low temperature $\left(4^{\circ} \mathrm{C}\right)$, the subcellular distribution of AZM in the soluble fraction is markedly lower; nevertheless, AZM concentration in cytosol is higher than in the extracellular concentration (Fig. 5). At a low temperature $\left(4^{\circ} \mathrm{C}\right)$, drug accumulation in cytosol was based on passive diffusion and trapping and/or binding to soluble protein rather than active influx. These findings indicate that both cytosolic parasitic bacteria and lysosomal parasitic bacteria in AMs are exposed to AZM and are sterilized.

\section{CONCLUSION}

The subcellular distribution of AZM in AMs has been described. This study suggests that high level of AZM accumulation in AMs is distribution in acidic organelles, such as lysosomes. These findings indicate that both cytosolic and lysosomal parasitic pathogens in AMs are exposed to AZM and are sterilized. Moreover, this study provides important information for optimizing the treatment for respiratory intra- cellular parasitic infections based on the cellular pharmacokinetics of antimicrobial agents in AMs.

Acknowledgment This work was supported in part by Grant-in-Aid (No. 20590039) for Scientific Research provided by Japan Society for the Promotion of Science.

\section{REFERENCES}

1) Bright GM, Nagel AA, Bordner J, Desai KA, Dibrino JN, Nowakowska J, Vincent L, Watrous RM, Sciavolino FC, English AR, Retsema JA, Anderson MR, Brennan LA, Borovoy RJ, Cimochowski CR, Faiella JA, Girard AE, Girard D, Herbert C, Manousos M, Mason R. Synthesis, in vitro and in vivo activity of novel 9-deoxo-9a-AZA-9a-homoerythromycin A derivatives; a new class of macrolide antibiotics, the azalides. J. Antibiot., 41, 1029-1047 (1988).

2) Hardy DJ, Hensey DM, Beyer JM, Vojtko C, McDonald EJ, Fernandes PB. Comparative in vitro activities of new 14-, 15-, and 16-membered macrolides. Antimicrob. Agents Chemother., 32, $1710-1719$ (1988).

3) Miyashita N, Fukano H, Yoshida K, Niki Y, Matsushima T. In vitro activity of cethromycin, a novel antibacterial ketolide, against Chlamydia pneumoniae. J. Antimicrob. Chemother., 52, 497-499 (2003).

4) Sato $\mathrm{T}$, Tateda $\mathrm{K}$, Kimura $\mathrm{S}$, Ishii $\mathrm{Y}$, Yamaguchi $\mathrm{K}$. In vitro intracellular activity and in vivo efficacy of modithromycin, a novel bicyclolide, against Legionella pneumophila. Antimicrob. Agents Chemother., 55, 1594-1597 (2011).

5) Chiu LM, Menhinick AM, Johnson PW, Amsden GW. Pharmacokinetics of intravenous azithromycin and ceftriaxone when administered alone and concurrently to healthy volunteers. J. Antimicrob. Chemother, 50, 1075-1079 (2002).

6) Girard AE, Girard D, English AR, Gootz TD, Cimochowski CR, Faiella JA, Haskell SL, Retsema JA. Pharmacokinetic and in vivo studies with azithromycin (CP-62,993), a new macrolide with an extended half-life and excellent tissue distribution. Antimicrob. Agents Chemother., 31, 1948-1954 (1987).

7) Bosnar M, Kelneric Z, Munic V, Erakovic V, Parnham MJ. Cellular uptake and efflux of azithromycin, erythromycin, clarithromycin, telithromycin, and cethromycin. Antimicrob. Agents Chemother., 49, 2372-2377 (2005).

8) Carbon C. Clinical relevance of intracellular and extracellular concentrations of macrolides. Infection, 23 (Suppl. 1), S10-S14 (1995).

9) Gladue RP, Bright GM, Isaacson RE, Newborg MF. In vitro and in vivo uptake of azithromycin (CP-62,993) by phagocytic cells: possible mechanism of delivery and release at sites of infection. Antimicrob. Agents Chemother., 33, 277-282 (1989).

10) Muto C, Liu P, Chiba K, Suwa T. Pharmacokinetic-pharmacodynamic analysis of azithromycin extended release in Japanese patients with common respiratory tract infectious disease. J. Antimicrob. Chemother., 66, 165-174 (2011).

11) Baldwin DR, Honeybourne D, Wise R. Pulmonary disposition of antimicrobial agents: methodological considerations. Antimicrob. Agents Chemother., 36, 1171-1175 (1992).

12) Gordon SB, Read RC. Macrophage defences against respiratory tract infections. Br. Med. Bull., 61, 45-61 (2002).

13) Nara C, Tateda K, Matsumoto T, Ohara A, Miyazaki S, Standiford TJ, Yamaguchi K. Legionella-induced acute lung injury in the setting of hyperoxia: protective role of tumour necrosis factor-alpha. $J$. Med. Microbiol., 53, 727-733 (2004).

14) Yamaguchi $\mathrm{H}$, Haranaga $\mathrm{S}$, Widen $\mathrm{R}$, Friedman $\mathrm{H}$, Yamamoto $\mathrm{Y}$. Chlamydia pneumoniae infection induces differentiation of monocytes into macrophages. Infect. Immun., 70, 2392-2398 (2002).

15) Mandell GL. Interaction of intraleukocytic bacteria and antibiotics. J. Clin. Invest., 52, 1673-1679 (1973).

16) Cook PJ, Andrews JM, Wise R, Honeybourne D. Distribution of 
cefdinir, a third generation cephalosporin antibiotic, in serum and pulmonary compartments. J. Antimicrob. Chemother., 37, 331-339 (1996).

17) Kikuchi E, Yamazaki K, Kikuchi J, Hasegawa N, Hashimoto S, Ishizaka A, Nishimura M. Pharmacokinetics of clarithromycin in bronchial epithelial lining fluid. Respirology, 13, 221-226 (2008).

18) Nicolau DP, Sutherland C, Winget D, Baughman RP. Bronchopulmonary pharmacokinetic and pharmacodynamic profiles of levofloxacin $750 \mathrm{mg}$ once daily in adults undergoing treatment for acute exacerbation of chronic bronchitis. Pulm. Pharmacol. Ther., 25, 94-98 (2012)

19) Ong CT, Dandekar PK, Sutherland C, Nightingale CH, Nicolau DP. Intrapulmonary concentrations of telithromycin: clinical implications for respiratory tract infections due to Streptococcus pneumoniae. Chemotherapy, 51, 339-346 (2005).

20) Ziglam HM, Baldwin DR, Daniels I, Andrew JM, Finch RG. Rifampicin concentrations in bronchial mucosa, epithelial lining fluid, alveolar macrophages and serum following a single $600 \mathrm{mg}$ oral dose in patients undergoing fibre-optic bronchoscopy. J. Antimicrob. Chemother., 50, 1011-1015 (2002).

21) Briones E, Colino CI, Lanao JM. Delivery systems to increase the selectivity of antibiotics in phagocytic cells. J. Control. Release, 125, 210-227 (2008).

22) Van Bambeke F, Barcia-Macay M, Lemaire S, Tulkens PM. Cellular pharmacodynamics and pharmacokinetics of antibiotics: current views and perspectives. Curr. Opin. Drug Discov. Devel., 9, 218-230 (2006).

23) Togami K, Chono S, Morimoto K. Distribution characteristics of clarithromycin and azithromycin, macrolide antimicrobial agents used for treatment of respiratory infections, in lung epithelial lining fluid and alveolar macrophages. Biopharm. Drug Dispos., 32, 389-397 (2011).

24) Togami K, Chono S, Morimoto K. Transport characteristics of clarithromycin, azithromycin and telithromycin, antibiotics applied for treatment of respiratory infections, in Calu-3 cell monolayers as model lung epithelial cells. Pharmazie, 67, 389-393 (2012).

25) Kohno Y, Yoshida H, Suwa T, Suga T. Uptake of clarithromycin by rat lung cells. J. Antimicrob. Chemother., 26, 503-513 (1990).

26) Bradford MM. A rapid and sensitive method for the quantitation of microgram quantities of protein utilizing the principle of proteindye binding. Anal. Biochem., 72, 248-254 (1976).

27) Togami K, Chono S, Seki T, Morimoto K. Intracellular pharmacokinetics of telithromycin, a ketolide antibiotic, in alveolar macrophages. J. Pharm. Pharmacol., 62, 71-75 (2010).

28) Seral C, Carryn S, Tulkens PM, Van Bambeke F. Influence of Pglycoprotein and MRP efflux pump inhibitors on the intracellular activity of azithromycin and ciprofloxacin in macrophages infected by Listeria monocytogenes or Staphylococcus aureus. J. Antimicrob. Chemother., 51, 1167-1173 (2003).

29) Moreau A, Le Vee M, Jouan E, Parmentier Y, Fardel O. Drug transporter expression in human macrophages. Fundam. Clin. Pharmacol., 25, 743-752 (2011).

30) Garver E, Hugger ED, Shearn SP, Rao A, Dawson PA, Davis CB, Han C. Involvement of intestinal uptake transporters in the absorption of azithromycin and clarithromycin in the rat. Drug Metab.
Dispos., 36, 2492-2498 (2008).

31) Lan T, Rao A, Haywood J, Davis CB, Han C, Garver E, Dawson PA. Interaction of macrolide antibiotics with intestinally expressed human and rat organic anion-transporting polypeptides. Drug Metab. Dispos., 37, 2375-2382 (2009).

32) Seithel A, Eberl S, Singer K, Auge D, Heinkele G, Wolf NB, Dorje F, Fromm MF, Konig J. The influence of macrolide antibiotics on the uptake of organic anions and drugs mediated by OATP1B1 and OATP1B3. Drug Metab. Dispos., 35, 779-786 (2007).

33) Hand WL, Hand DL. Characteristics and mechanisms of azithromycin accumulation and efflux in human polymorphonuclear leukocytes. Int. J. Antimicrob. Agents, 18, 419-425 (2001).

34) Chanteux H, Paternotte I, Mingeot-Leclercq MP, Brasseur R, Sonveaux E, Tulkens PM. Cell handling, membrane-binding properties, and membrane-penetration modeling approaches of pivampicillin and phthalimidomethylampicillin, two basic esters of ampicillin, in comparison with chloroquine and azithromycin. Pharm. Res., 20, 624-631 (2003).

35) Poole B, Ohkuma S. Effect of weak bases on the intralysosomal $\mathrm{pH}$ in mouse peritoneal macrophages. J. Cell Biol., 90, 665-669 (1981).

36) Yoshida H, Okumura K, Hori R. Contribution of monoamine oxidase (MAO) to the binding of tertiary basic drugs in isolated perfused rat lung. Pharm. Res., 7, 398-401 (1990).

37) Vestal RE, Kornhauser DM, Shand DG. Active uptake of propranolol by isolated rabbit alveolar macrophages and its inhibition by other basic amines. J. Pharmacol. Exp. Ther., 214, 106-111 (1980).

38) Ishizaki J, Yokogawa K, Hirano M, Nakashima E, Sai Y, Ohkuma S, Ohshima T, Ichimura F. Contribution of lysosomes to the subcellular distribution of basic drugs in the rat liver. Pharm. Res., 13, 902-906 (1996).

39) Barcia-Macay M, Mouaden F, Mingeot-Leclercq MP, Tulkens PM, Van Bambeke F. Cellular pharmacokinetics of telavancin, a novel lipoglycopeptide antibiotic, and analysis of lysosomal changes in cultured eukaryotic cells (J774 mouse macrophages and rat embryonic fibroblasts). J. Antimicrob. Chemother., 61, 1288-1294 (2008).

40) Lemaire S, Tulkens PM, Van Bambeke F. Cellular pharmacokinetics of the novel biaryloxazolidinone radezolid in phagocytic cells. studies with macrophages and polymorphonuclear neutrophils. Antimicrob. Agents Chemother., 54, 2540-2548 (2010).

41) Ishizaki J, Yokogawa K, Ichimura F, Ohkuma S. Uptake of imipramine in rat liver lysosomes in vitro and its inhibition by basic drugs. J. Pharmacol. Exp. Ther., 294, 1088-1098 (2000).

42) Haran G, Cohen R, Bar LK, Barenholz Y. Transmembrane ammonium sulfate gradients in liposomes produce efficient and stable entrapment of amphipathic weak bases. Biochim. Biophys. Acta, 1151, 201-215 (1993).

43) Milatovic D. Intraphagocytic activity of erythromycin, roxithromycin and azithromycin. Eur. J. Clin. Microbiol. Infect. Dis., 9, 33-35 (1990).

44) Steinman RM, Brodie SE, Cohn ZA. Membrane flow during pinocytosis. A stereologic analysis. J. Cell Biol., 68, 665-687 (1976).

45) Togami K, Chono S, Morimoto K. Aerosol-based efficient delivery of azithromycin to alveolar macrophages for treatment of respiratory infections. Pharm. Dev. Technol., 1-5 (2012). 